\title{
The Study of Pilotis and Reentrant Buildings Effects on Kinetic Energy and Wind Velocity in Urban Canyons
}

\author{
${ }^{1}$ Elahe Mirabi, ${ }^{2}$ Saba abdi \\ ${ }^{1,2}$ Energy and Architecture, Ilam University, Ilam
}

\begin{abstract}
The form of urban canyons has so many effects on climate and ventilation of urban canyons. Most of the buildings in urban area have pilotis or balcony (reentrant), and a few of them are rigid and have even surfaces. For this reason, the pilotis form, the reentrant form and the mixed form (pilotis and reentrant) have been modeled in this article with ENVI-met software. In this article, the effects of structural forms on wind velocity and kinetic energy at 1 meter above ground level (pedestrian level) has been studied using ENVI-met software. Due to the difference of these alterations in north, south and center of urban canyon, each of them has been studied separately. According to these studies, it can be observed that the pilotis form increases the kinetic energy and wind velocity. In model 1 the kinetic energy in the south of urban canyon increases up to $7.65 \mathrm{M}^{2} / \mathrm{M}^{3}$. The reentrant form decreases the kinetic energy and wind velocity in most regions of the urban canyon. The combination of reentrant form and pilotisis creates an average mode. Considering the results of the study, it can be said that the form of urban canyons must be selected due to the climate of that region.
\end{abstract}

Key Words: Urban Canyon, Pilotis, Reentrant, Kinetic Energy and Wind Velocity, ENVImet.

\section{Introduction}

The urban form has so many effects on the urban climate, because it can change the urban temperature (Taleb, \& Abu-Hijleh, 2013). In fact, this urban form takes shape by the form and distribution of buildings. So, it can be said that the distribution of buildings in a city affects the climate (Givoni, 1998). On the other hand, the study of air quality of the cities is so important, because due to the global statistics shows that about 50 to 60 percent of the world population lives in cities and this population is growing rapidly (Taleb, \& Abu-Hijleh, 2013).

The shape of the city has a great effect on the wind velocity and direction and subsequently on the urban ventilation. It can be said that the wind behavior is a resultant of the shape of the city. Comparison between the wind existence and absence shows its effect on the removal of major fluctuation of the temperature and heat decreasing (Taleb, \& Abu-Hijleh, 2013). On the other hand, the texture of the 
$5^{\text {th }}$ International Conference on Civil Engineering, Architecture and Urban Planning Elites

earth surface determines the air velocity and acceleration. Also, the condition of wind blowing in city, especially in passages and streets, has direct effects on the citizens' thermal comfort condition, the amount of heating and cooling energy consumption of buildings and the urban air pollution concentration (Eeftens et al., 2013).

The buildings' distribution manner determines the amount of solar energy absorption in urban spaces and the formation of airflow in the city. The role of environment in the dispersion of atmospheric pollutants and particulate matters is determined due to the amount of sun radiation and airflow between buildings. The city's reaction to sun radiation and airflows can be controlled by urban design. The optimized urban design can decrease the energy consumption of the city and neutralize the negative effects of Thermal Island (Gago, Roldan, Pacheco-Torres, \& Ordóñez, 2013).

Most of the existing buildings in the city have pilotisis or reentrant balconies, and a few of them are rigid companion with even surfaces. For this reason, the pilotis form, the reentrant form and the mixed form (pilotis and reentrant) have been simulated in this article with ENVI-met software. The effects of structural forms on wind velocity and kinetic energy at 1 meter above ground level (pedestrian level) has been studied using ENVI-met software. Due to the difference of these alterations in north, south and center of urban canyon, each of them has been studied separately.

\section{Literature Review}

Rajagopalan et al. has studied the effects of Urban geometry and airflow on Thermal Island in a research in one of the growing cities in south of Malaysia. Their results show that the wind existence in the contexture of the city helps decreasing the undesirable effects of Thermal Island. They also have concluded that in urban planning the regions with low velocity wind must be covered by shadow and tropical trees (Rajagopalan, Lim, \& Jamei, 2014).

Researchers have worked on the topic of urban canyons in some researches. Fernando Martin et al. have studied the airflow model in symmetric and asymmetric urban canyons using Fluent software. In this research the airflow has been modeled in five consecutive urban canyons and in two symmetric and asymmetric patterns (Santiago \& Martín, 2005). Kambiz Nazridoust has studied the airflow and transmission of pollution in urban canyons using Fluent software and in this research the effects of buildings' height and wind velocity on the transmission of pollution has been checked out (Nazridoust \& Ahmadi, 2006). Xiaomin Xie et al. have used numerical models of turbulence to study the effects of buildings' shape on air quality in urban canyons. They have studied the effects of the roof shape and the arrangement of surrounding buildings on the amount of pollution' distribution (Xie, Huang, \& Wang, 2005).

Edward $\mathrm{Ng}$ et al. have studied the solutions for improvement the airflow in dense urban regions in Hong Kong regarding to morphology and roughness of urban surfaces. They have suggested some solutions as making balcony (platform) for air conditioning, making deflection parallel to the prevailing wind, determining open urban areas, making holes in the surfaces that facing the wind, permitting the open areas to 
$5^{\text {th }}$ International Conference on Civil Engineering, Architecture and Urban Planning Elites

connect for urban regions ventilation and making distances between buildings for creating blindfold especially in hot and humid dense cities (Ng et al., 2011). Fazia AliToudert has studied in Ghardaïa, Algeria, the relation between the streets' height to width ratio and the orientation of the streets towards the sun with thermal comfort using ENVI-met (Ali-Toudert \& Mayer, 2006). Hedquist et al. using ENVI-met and field studies have studied the temperature changes in dense regions and the effects of increasing buildings' height on the surfaces (Hedquist et al., 2009). Azli abd razak et al. has studied the urban blocks layout, the height of and distance between them and the effects of them on airflow patterns using ENVI-met (Razak, Hagishima, Ikegaya, \& Tanimoto, 2013).

\section{Urban Canyon}

Most of metropolises have inappropriate urban planning that causes deep and narrow urban canyons and are still suffering from ventilation and air quality problems. The air quality of these canyons is so dependent on the right interaction of wind and surrounding buildings and the geometry of canyon (Chan, So, \& Samad, 2001).

The airflow pattern and subsequently air pollution dispersion is not only by the effect of the geometry of the buildings near canyons, but also can be affected by the other surrounding buildings. Some patterns have similar characteristics in the amount of pollution dispersion, but the densities of pollution positions are different from each other due to the air flow pattern. The position of the main circular flow in urban canyons can be varied due to the surrounding buildings shape. By comparison the amount of pollution density at the canyon center, it was seen that the most amount of pollution occurred in the time that the center of formed vortex flow climbed up by the effect of the around flows, so the intensity of airflow in the ground level was weakened (Xie, Huang, \& Wang, 2005).

The neutral and stable condition in urban canyons causes the remaining of pollution in canyon-shaped streets and for recovery and removal of these pollution we can make a little turbulence in air layers. Trees also can decrease the air changes ratio in canyon-shaped streets and can increase the pollution dispersion in the side of the windward walls (Eeftens et al., 2013).

Visibility and orientation ratio in urban streets is an important and effective factor on the airflow quality and consequently the citizens' thermal comfort. If the street width is less than 3 times the average height of adjacent buildings, the airflow in that way will be canalized and expanded, and if the distance between buildings is more than $50 \%$ of their length, this phenomenon does not occur (Eeftens et al., 2013).

\section{Building sprawls}

Taking into consideration the buildings' ventilation in city scale, the position of buildings' sprawls gets so more importance. There are some situation in which building openings are located in a high pollution-dispersion position and consequently the level of air pollution in the building increases. So, the prediction of airflow pattern and 
$5^{\text {th }}$ International Conference on Civil Engineering, Architecture and Urban Planning Elites

pollution distribution and the position of pollution density is so important (Taleb, \& Abu-Hijleh, 2013). The pollution density in the low atmosphere levels not only is hazardous for the health of pedestrians, but also can affect the air quality in the building through the ventilation systems. So, the improvement of the pollution distribution capacity in the low atmosphere levels in high-rise urban settings is essential (Hang el al., 2012).

The dispersion of air pollution is dependent significantly on the permeability of urban canyons. The results of modeling show that the direction of prevailing wind and the urban permeability are effective on the dispersion of pollution in canyon-shaped streets (Yuan, Ng, \& Norford, 2014). With the observance of air movement strategies (e.g. buildings' separation, making porosity, making empty platforms) the turbulence can be created in air layers and it can be said that the concentration of pollution on street level is related to canyon-shaped streets' permeability (Santiago \& Martín, 2005).

\section{Urban Bodies}

It is specified in studies that the wind pressure on buildings is by influenced by different appurtenances like balconies or the rippling of building surfaces and the balconies are more effective than uniform rippling on decreasing the pressure on buildings (Aida \& Gotoh, 1982). Furthermore, in the condition that the unilateral ventilation strategy is the only choice, the effects of the ventilation function can be improved by the bulging elements of façade like balconies (Mohamed, King, Behnia, \& Prasad, 2011).

According to assessments carried out, various elements on facades such as balconies, can be effective on averaged-wind pressure (cp) and consequently on the air flow pattern (Murakami, 1990) (Blocken, Janssen, \& Van Hooff, 2012) or the range of turbulence intensity is influenced by the surfaces of the ground and walls complications (Blocken, Carmeliet, \& Stathopoulosc, 2007) and even urban physics can contribute to different lines of building and environmental comfort from building energy consumption to pollutant dispersion and pedestrian comfort (Moonen et al., 2012).

The comfort and safety of the wind are so significant necessities in urban areas (Yoshiea et al., 2007) (Janssen, Blocken, \& Van Hooff, 2013). The study of wind comfort includes the static meteorology information with aerodynamics information and the comfort amount. The aerodynamics information usually includes two parts: the portion relating to the district and the portion relating to the project. The district portion presents the changes in wind statistics that result in local city planning. In fact it shows the shape of buildings and can be obtained by wind tunnel test or by numerical modeling by CFD (Yoshiea et al., 2007). So many CFD studies have been fulfilled in the past about the wind condition on the pedestrian level around the buildings or complex urban regions like figure 1 (Lin et al., 2014) (Bruse, 2018) (Hedquist et al., 2009). 
a Front view

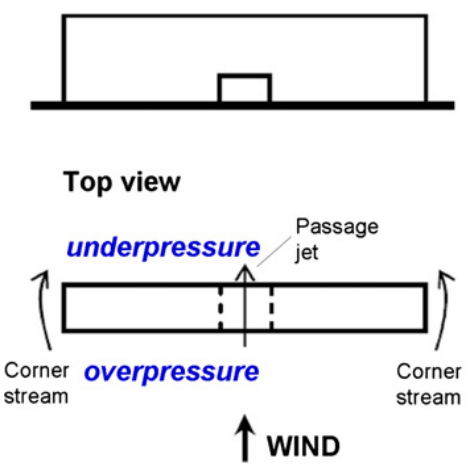

b Front view

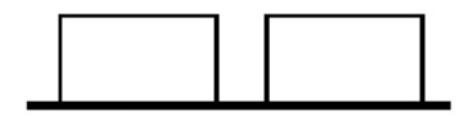

Top view

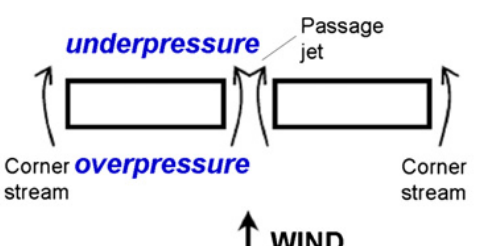

$\uparrow$ WIND
C Front view

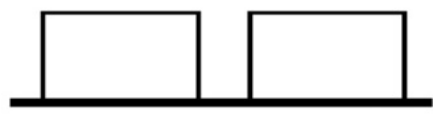

Top view

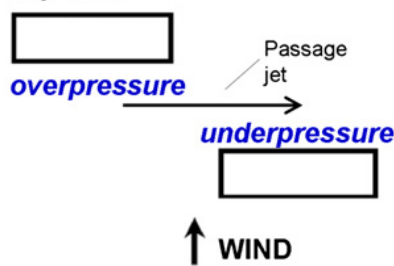

Figure 1: schematic presentation of building forms exposed to wind disturbance on pedestrian level

Most of the studies have been done on the wind velocity condition on pedestrian level. They usually have concentrated only on the wind velocity near the ground level. We now know that paying attention to the wind condition and wind comfort and safety in tall buildings' balconies is so important, because these balconies can confront the strong winds. Because of the reduction in wind discomfort in balconies, different conditions like enclosure of balcony or adding partitions can be considered (Hedquist et al., 2009). We can see that in today's urban environment, the vertical growth of buildings, especially the dense residential buildings, accompanied by using natural light and natural ventilation for indoor environment quality can be an appropriate solution if it is planned and managed well (Mohamed, King, Behnia, \& Prasad, 2011).

The relation between the variety of building heights and pollution dispersion is not still clear. The results of some researches show that the variety in buildings' heights reduces the airflow capacity for pollution dilution and on the other side increase the turbulence of the airflow. Since the both primary flow and turbulent flow have vital roles in clearing the pollution in urban regions, so the changes in buildings' height can either reduce or increase the ventilation capacity (Hang el al., 2012). The variety of buildings' height improves the vertical air exchange along the street, but it weakens the horizontal flows along the street and in return improves the ventilation in the streets opposite to high-rise buildings and levelled down the ventilation in the dorsal streets. General conclusion about the effect of buildings' height variety in total ventilation of urban canyons is so difficult in comparison with the uniform-height buildings (Razak, Hagishima, Ikegaya, \& Tanimoto, 2013).

\section{R Method}

In this article two important factors-wind velocity and kinetic energy in urban canyon has been investigated by the effect of buildings' mass. The effects of pilotis- 
shaped buildings (having opening) on the existing condition in urban canyon have been compared with those of reentrant form, using ENVI-met software. A basic model (Figure 2-a) has been considered that includes rigid volumes in both sides of urban canyon. First model (Figure 2-b) is the sideway buildings with pilotis. The second model (Figure $2-c$ ) is the sideway buildings with reentrant (balcony-shaped). The third model (Figure 2-d) is the combination of first and second model, including pilotis-reentrant sideway buildings. At last the effects of these four statuses have been compared to each other. But, we should take into consideration that the changes have been studied in 1 meter above ground level and in pedestrian level. For a more accurate study, the changes in kinetic energy and wind velocity have been checked in southern part (Figure 3-a), center part (Figure 3-b) and northern part (Figure 3-c) of urban canyon in 11 points. The northern and southern parts are more important because of pedestrian passing.

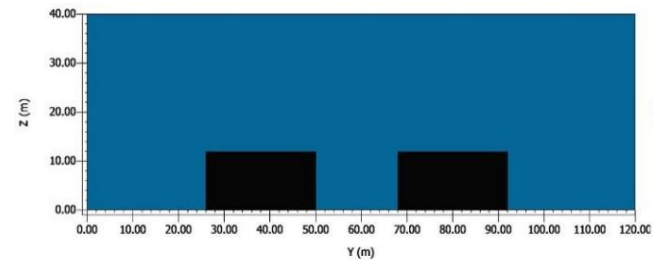

a

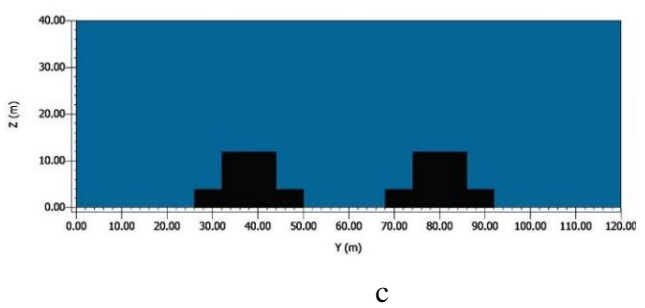

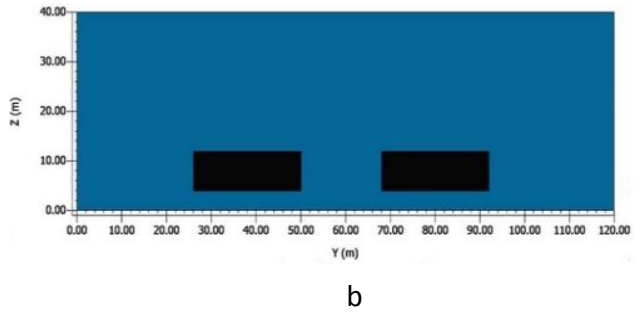

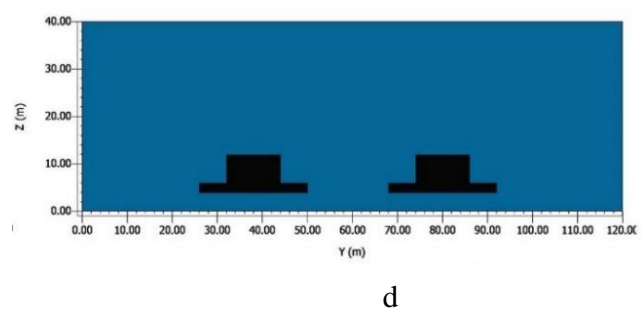

Fig. 2. Modelled Forms (a: Basic model, b: Pilot model, c: Reentrant model, d: Mixed Model) 

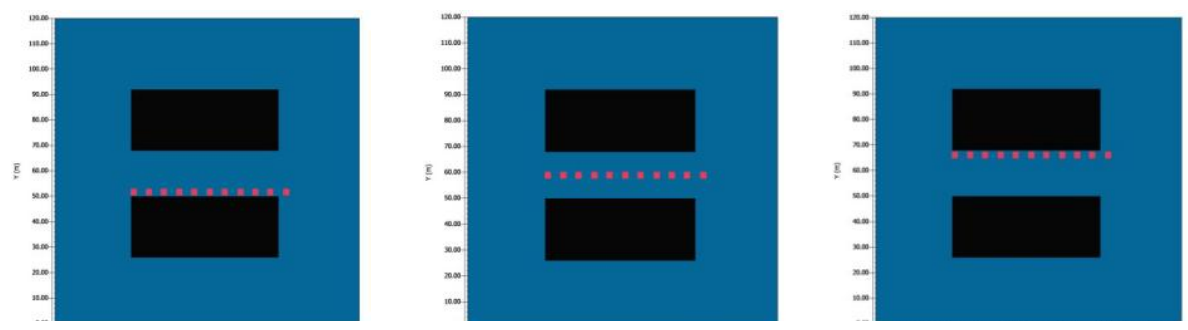

Fig. 3. Studied points (a: Points in Southern Part, b: Points in Center Part, c: Points in Northern Part)

\section{Software Introduction}

ENVI-met software has the capability of studying different parameters for urban blocks with different forms. ENVI-met is an urban simulation software, developing by Dr. Michael Bruce. This software has enough ability for calculation of micro-climates in cities with complex structure on the basis of fluid dynamics and thermodynamics principles and foundations (Bruse, 2018). Some studies using ENVI-met have been mentioned in introduction.

One of these researches has been fulfilled by Hedquist et al. using ENVI-met and field studies to check the changes of temperature in dense regions and the effects of buildings' height increasing on the surfaces (Hedquist et al., 2009). Azli Abd Razak et al. have studied the urban blocks layout, the height of and distance between them and the effects of all of them on the airflow pattern by this software (Razak, Hagishima, Ikegaya, \& Tanimoto, 2013). Jelle Hofman et al. using this software to study the density of tree crowns in dispersing the pollution in urban blocks (Hofman \& Samson, 2014). For modeling the wind flow, the basic concept of the turbulence of incompressible non-hydrostatic 3-D flow has been scrutinized by Navier-Stokes equations (1b), (1a), and (1c): (Bruse \& Fleer, 1998). This software follows up these formulas:

$$
\begin{aligned}
& \frac{\partial u}{\partial t}+u_{i} \frac{\partial u}{\partial x_{i}}=-\frac{\partial p^{2}}{\partial x}+K_{m}\left(\frac{\partial^{2} u}{\partial x_{i}^{2}}\right)+F\left(v-v_{g}\right) \\
& \text { - } \mathrm{S}_{\mathrm{u}} \\
& \frac{\partial v}{\partial t}+u_{i} \frac{\partial v}{\partial x_{i}}=-\frac{\partial p^{2}}{\partial y}+K_{m}\left(\frac{\partial^{2} v}{\partial x_{i}^{2}}\right)+F\left(u-u_{g}\right) \\
& -S_{v} \\
& \frac{\partial w}{\partial t}+u_{i} \frac{\partial w}{\partial x_{i}}=-\frac{\partial p^{2}}{\partial z}+K_{m}\left(\frac{\partial^{2} w}{\partial x_{i}^{2}}\right)+g \frac{\theta(z)}{\theta_{r e f}(z)} \\
& -S_{w} \\
& \frac{\partial u}{\partial x}+\frac{\partial v}{\partial y}+\frac{\partial w}{\partial z}=0
\end{aligned}
$$


$5^{\text {th }}$ International Conference on Civil Engineering, Architecture and Urban Planning Elites

In these formulas $f\left(=104 \mathrm{sec}^{-1}\right)$ is Carioles parameter, $P^{\prime}$ is turbulence local pressure, and $\theta$ is the potential temperature in $\mathrm{Z}$ level. The reference temperature $\vartheta_{\text {ref }}$ must be prepared in average meteorology condition in 1-D model parallel to the primary model. Air density, $\rho$ in compressible Navies-Stokes equations can be removed and the Bossiness approximation (buoyancy) can be used. This approximation creates an additional resource, $W$, in vertical movement of thermal force equation. This equation is used for the preservation of time steps in mass maintenance model (Bruse \& Fleer, 1998).

\section{Results, discussion and data analysis}

Firstly, the kinetic energy in different models has been studied and compared to each other (Figure 4). Regarding to Figure 4-a, the kinetic energy has the most amount in northern part of urban canyon in basic model. In pilotis model (Figure 4-b) we can see that the kinetic energy in southern part has more amount than that of basic model. In this model the kinetic energy is almost the same in whole urban canyon. In Reentrant model (Figure 4-c) the kinetic energy has been decreased in comparison with basic model. But the changes of kinetic energy in this model have more similarity in whole urban canyon in comparison with basic model. In mixed model (Figure 4-d), it can be seen that the kinetic energy has increased in comparison with basic model. The most kinetic energy has been seen in the southern part of the canyon. The kinetic energy of this model (Figure 4-d) is less than Reentrant model (Figure 4-c). Since both pilotis model and mixed model have pilotis, it can be said that the difference between these two models' kinetic energy is due to the reentrant form in combined model.
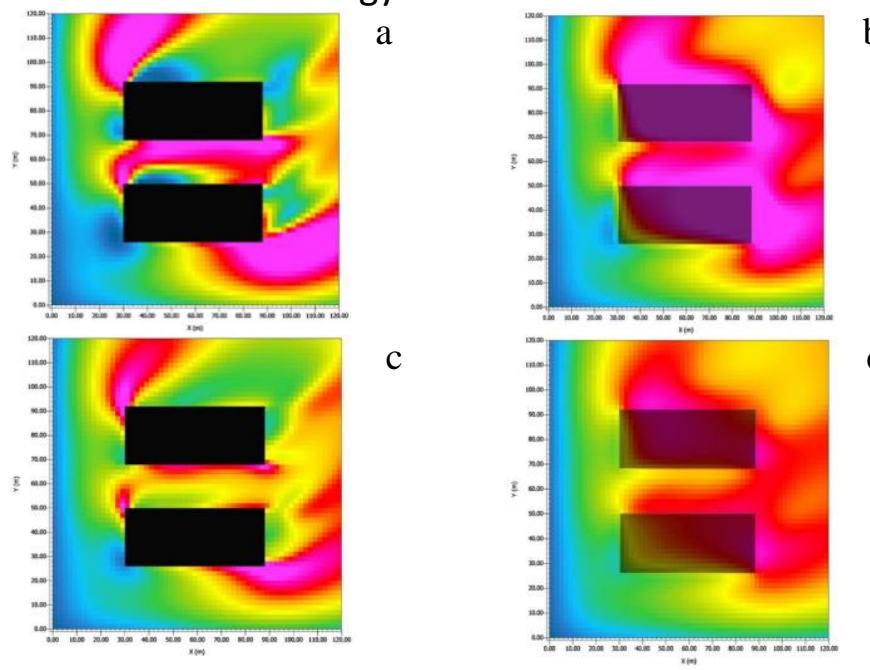

b TKE

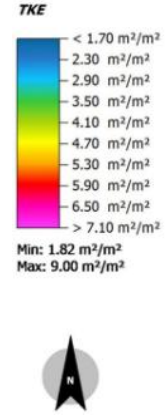

Fig. 4. Kinetic energy contours in (a: Basic, b: Pilot, c: Reentrant and d: Mixed Model)

Regarding to Figure 5, it can be said that pilotis model has the most kinetic energy in southern part of urban canyon. The kinetic energy has increased up to $7.65 \mathrm{M}^{2} / \mathrm{M}^{3}$ in this model. In all pilotis, reentrant and mixed models the kinetic energy have increased in comparison with basic model accompanied by a rigid volume. However, 
$5^{\text {th }}$ International Conference on Civil Engineering, Architecture and Urban Planning Elites

the changes of kinetic energy in the southern part of basic model are more than others.

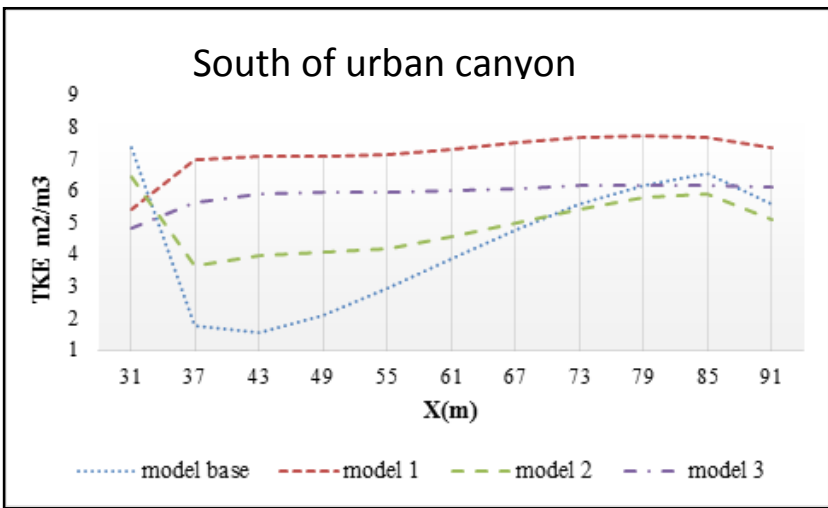

Fig. 5. Kinetic Energy Comparison in All Models in the South of Urban Canyons

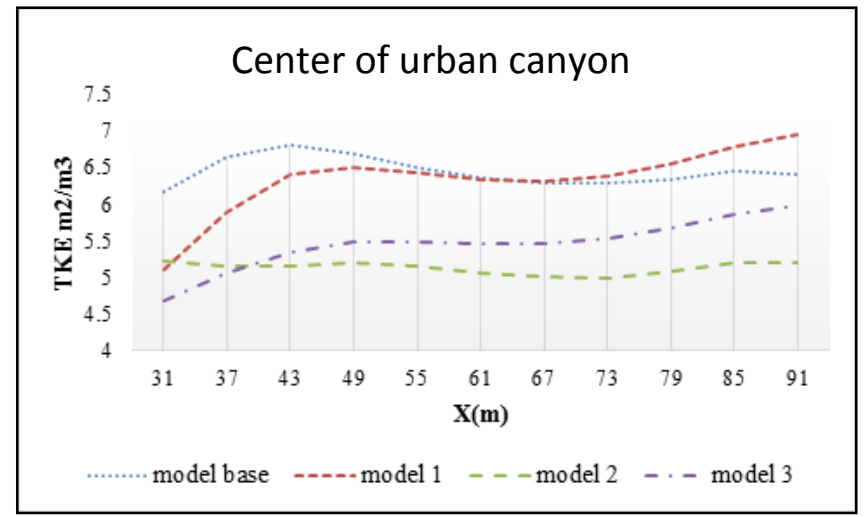

Fig. 6. Kinetic Energy Comparison in All Models in the Center of Urban Canyons

Regarding to Figure 6, the basic model and pilotis model (model 1 ) have the most kinetic energy in the center of urban canyons. The kinetic energy in pilotis model has been surged up to $6.96 \mathrm{M}^{2} / \mathrm{M}^{3}$. Pilotis model has the most fluctuation and changes of kinetic energy. Chart trend in pilotis model is similar to that of mixed model. The basic model has the most kinetic energy in the north of urban canyon. We can see in all three graphs in which pilotis and mixed models have similar trends. 


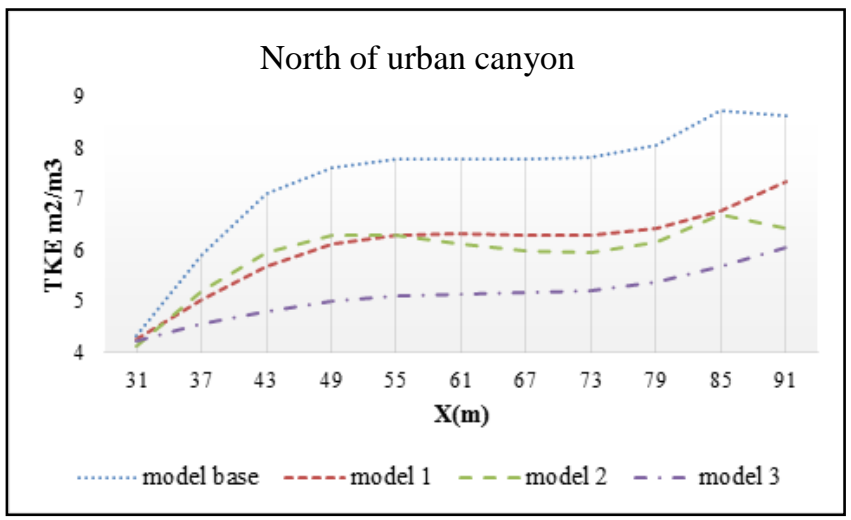

Fig. 7. Kinetic Energy Comparison in All Models in the North of Urban Canyons

Regarding to Figure 8 , it is interesting to notice that the most amount of wind velocity in basic model is in the northern part of urban canyon. In pilotis model (Figure 8-a) the most amount of wind velocity can be found in both northern and southern part of urban canyon and the wind velocity decrease in the central part. The changes of wind velocity in reentrant model (Figure 8-c) and basic model are in a harmony. But the wind velocity at 1 meter above ground level in mixed model decreases in comparison with basic model. We can find that the wind velocity changes in urban canyon in mixed model (Figure 8-d) are similar to pilotis model (Figure 8-b). But we can find that the amount of wind velocity decreases in mixed model in comparison with pilotis model.
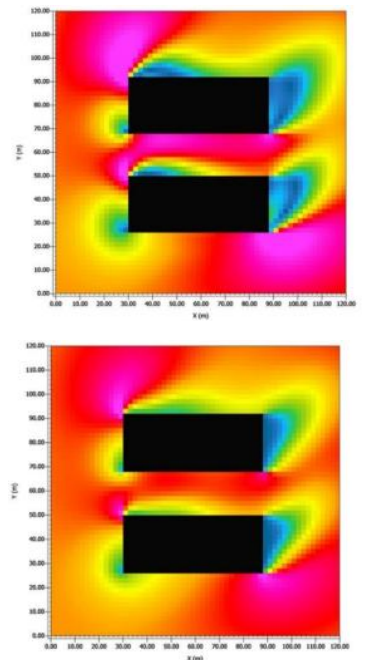

a

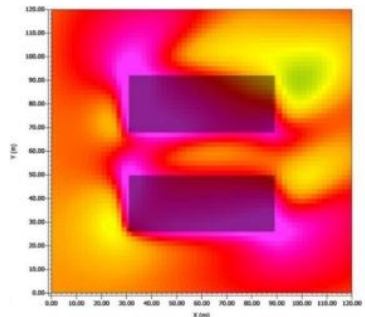

c

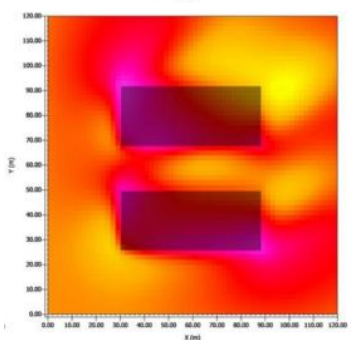

b

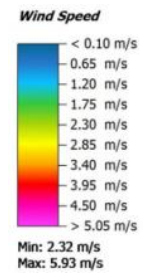

d

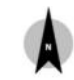

Fig. 8. Wind Velocity contours in (a: Basic model, b: Pilot model, c: Reentrant model, d: Mixed Model)

It can be found in Figure 9 that pilotis model and mixed model have respectively the most amount of wind velocity in the north of urban canyon. The wind velocity has changed from $5.27 \mathrm{~m} / \mathrm{s}$ to $3.51 \mathrm{~m} / \mathrm{s}$ in pilotis model. The chart trends in these two models are similar. Regarding to Figure 10, the basic model has the most amount of 
$5^{\text {th }}$ International Conference on Civil Engineering, Architecture and Urban Planning Elites

wind velocity in the center of urban canyon. The wind velocity has decreased in the center of urban canyon in pilotis and mixed models. Regarding to Figure 11 the basic and pilotis models have the most wind velocity. Also, it can be found from this chart that the changes in pilotis and mixed models are similar.

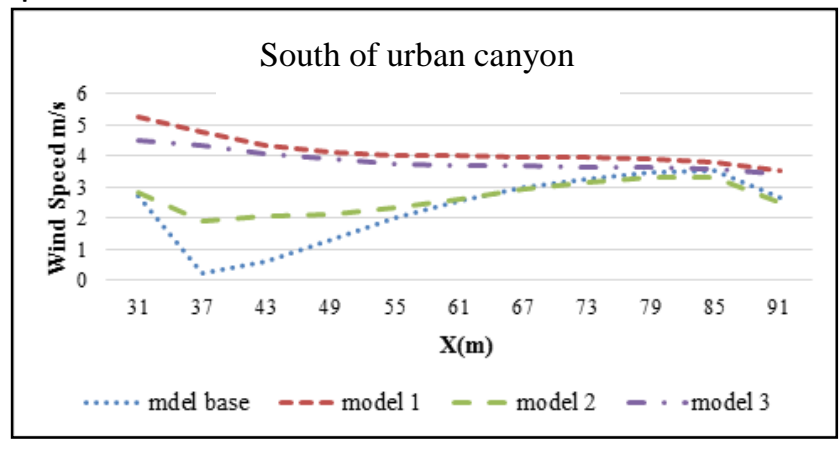

Fig. 9. Wind Velocity Comparison in All Models in the South of Urban Canyons

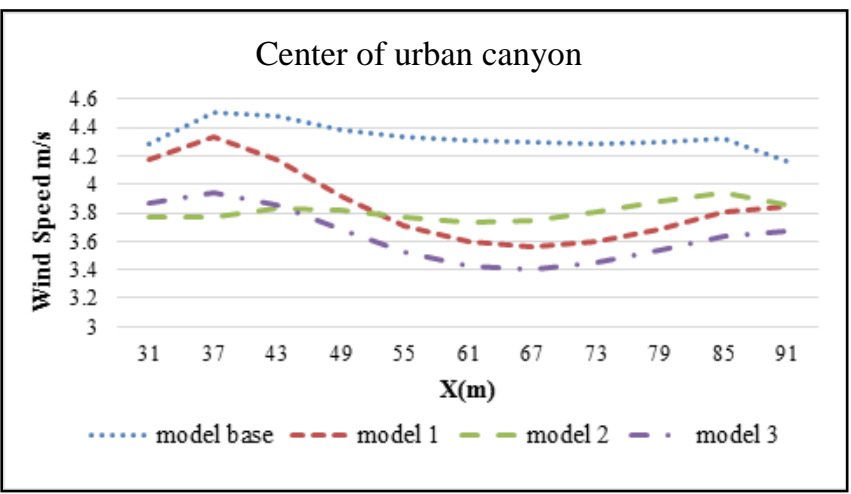

Fig. 10. Wind Velocity Comparison in All Models in the Center of Urban Canyons

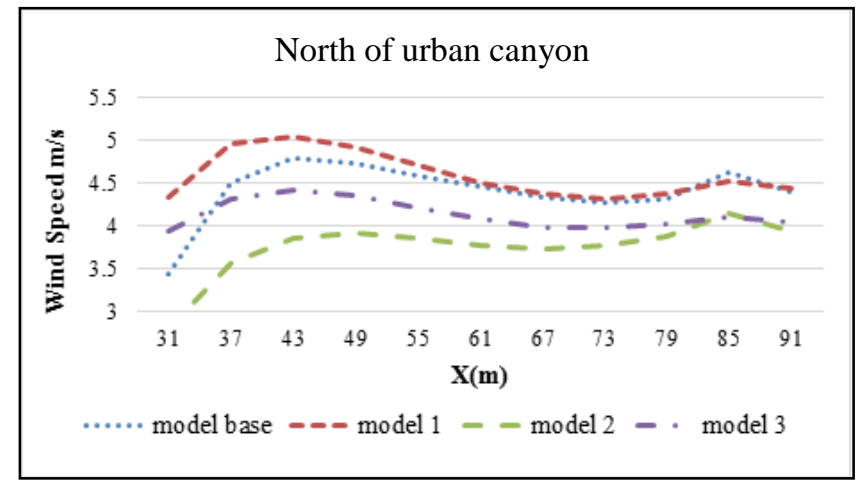

Fig. 11. Wind Velocity Comparison in All Models in the North of Urban Canyons.

After fulfilling all these simulations and investigations, it can be said that the effect of pilotis is much more than reentrant form in 1 meter above ground level. The combination of pilotis with reentrant form can decrease the effects of single pilotis. 
$5^{\text {th }}$ International Conference on Civil Engineering, Architecture and Urban Planning Elites

We can use reentrant forms in buildings in the parts of urban canyons that need the decreasing in wind velocity. On the other hand, the amount of kinetic energy and wind velocity in the north, center and south of urban canyon are different from each other, so the pedestrian cross roads must be chosen regarding to each urban form.

\section{Conclusion}

Most of the buildings in urban area have pilotis or balcony (reentrant), and a few of them are rigid and have even surfaces. The study and comparison the effects of pilotis form, reentrant form and mixed form with those of rigid form on the wind velocity and kinetic energy at 1 meter above ground level show that the pilotis form increase the wind velocity and the kinetic energy. The kinetic energy in pilotis model increases up to $7.65 \mathrm{M} 2 / \mathrm{M} 3$ in the southern part of urban canyon. The reentrant form can decrease the wind velocity and kinetic energy in most parts of urban canyons. The combination of reentrant form and pilotis creates a middle condition. This combination can decrease the effects of single pilotis. We can use reentrant buildings in the various parts of urban canyons that need the decreasing wind velocity. On the other hand, the amount of kinetic energy and wind velocity in the north, center and south of urban canyon are different from each other, so the pedestrian crossroads must be chosen regarding to each urban form. Finally, and due to these investigations, it can be said that each urban form must be selected regarding to that region's climate condition.

\section{References}

Aida, M., \& Gotoh, K. (1982). Urban albedo as a function of the urban structure-a two-dimensional numerical simulation. Boundary-layer meteorology, 23(4), 415-424.

Ali-Toudert, F., \& Mayer, H. (2006). Numerical study on the effects of aspect ratio and orientation of an urban street canyon on outdoor thermal comfort in hot and dry climate. Building and environment,41(2), 94-108. doi: 10.1016/j.buildenv.2005.01.013*

Blocken, B., Carmeliet, J., \& Stathopoulos, T. (2007). CFD evaluation of wind speed conditions in passages between parallel buildings-effect of wall-function roughness modifications for the atmospheric boundary layer flow. Journal of Wind Engineering and Industrial Aerodynamics, 95(9-11), 941-962. doi: 10.1016/j.jweia.2007.01.013*

Blocken, B., Janssen, W. D., \& van Hooff, T. (2012). CFD simulation for pedestrian wind comfort and wind safety in urban areas: General decision framework and case study for the Eindhoven University campus. Environmental Modelling \& Software, 30, 15-34. doi: 10.1016/j.envsoft.2011.11.009*

Bruse, M., \& Fleer, H. (1998). Simulating surface-plant-air interactions inside urban environments with a three dimensional numerical model. Environmental modelling \& software, 13(3-4), 373-384. doi: 10.1016/S1364-8152(98)00042-5*

Chan, A. T., So, E. S., \& Samad, S. C. (2001). Strategic guidelines for street canyon geometry to achieve sustainable street air quality. Atmospheric Environment, 35(24), 4089-4098. doi: 10.1016/S1352-2310(01)00212-6* 
$5^{\text {th }}$ International Conference on Civil Engineering, Architecture and Urban Planning Elites

Eeftens, M., Beekhuizen, J., Beelen, R., Wang, M., Vermeulen, R., Brunekreef, B., Huss, A., \& Hoek, G. (2013). Quantifying urban street configuration for improvements in air pollution models. Atmospheric Environment, 72, 1-9. doi: 10.1016/j.atmosenv.2013.02.007*

Gago, E. J., Roldan, J., Pacheco-Torres, R., \& Ordóñez, J. (2013). The city and urban heat islands: A review of strategies to mitigate adverse effects. Renewable and Sustainable Energy Reviews, 25, 749-758. doi: 10.1016/j.rser.2013.05.057*

Givoni, B. (1998). Climate Considerations in Building and Urban Design, New York: John Wiley \& Sons.

Hang, J., Li, Y., Sandberg, M., Buccolieri, R., \& Di Sabatino, S. (2012). The influence of building height variability on pollutant dispersion and pedestrian ventilation in idealized high-rise urban areas. Building and Environment, 56, 346-360. doi: 10.1016/j.buildenv.2012.03.023*

Hedquist, B. C., Di Sabatino, S., Fernando, H. J. S., Leo, L. S., Brazel, A. J., \& dei Materiali, D. D. S. (2009, June). Results from the Phoenix Arizona urban heat island experiment. In The seventh International Conference on Urban Climate, Yokohama, Japan, 29, 1-4.

Hofman, J., \& Samson, R. (2014). Biomagnetic monitoring as a validation tool for local air quality models: a case study for an urban street canyon. Environment international, 70, 50-61. doi: 10.1016/j.envint.2014.05.007*

Janssen, W. D., Blocken, B., \& van Hooff, T. (2013). Pedestrian wind comfort around buildings: Comparison of wind comfort criteria based on whole-flow field data for a complex case study. Building and Environment, 59, 547-562. doi: 10.1016/j.buildenv.2012.10.012*

Lin, M., Hang, J., Li, Y., Luo, Z., \& Sandberg, M. (2014). Quantitative ventilation assessments of idealized urban canopy layers with various urban layouts and the same building packing density. Building and Environment, 79, 152-167. doi: 10.1016/j.buildenv.2014.05.008*

Michael, Bruse. (2018 July 7). Retrieved from https://www.envi-met.com

Mohamed, M. F., King, S., Behnia, M., \& Prasad, D. (2011, November). A study of single-sided ventilation and provision of balconies in the context of high-rise residential buildings. In World Renewable Energy Congress-Sweden; 8-13 May; 2011; Linköping; Sweden, 057, 1954-1961. doi: 10.3384/ecp110571954*

Moonen, P., Defraeye, T., Dorer, V., Blocken, B., \& Carmeliet, J. (2012). Urban Physics: Effect of the micro-climate on comfort, health and energy demand. Frontiers of Architectural Research, 1(3), 197-228. doi: 10.1016/j.foar.2012.05.002*

Murakami, S. (1990). Computational wind engineering. Journal of Wind Engineering and Industrial Aerodynamics, 36, 517-538. doi: 10.1016/0167-6105(90)90335$A^{*}$

Nazridoust, K., Ahmadi, G. (2006). Airflow and pollutant transport in street canyons. Wind Engineering and Industrial Aerodynamics, 94, 491-522. doi: 10.1016/j.jweia.2006.01.012* 
$5^{\text {th }}$ International Conference on Civil Engineering, Architecture and Urban Planning Elites

Ng, E., Yuan, C., Chen, L., Ren, C., \& Fung, J. C. (2011). Improving the wind environment in high-density cities by understanding urban morphology and surface roughness: a study in Hong Kong. Landscape and Urban planning, 101(1), 5974. doi: 10.1016/j.landurbplan.2011.01.004*

Rajagopalan, P., Lim, K. C., \& Jamei, E. (2014). Urban heat island and wind flow characteristics of a tropical city. Solar Energy, 107, 159-170. doi: 10.1016/j.solener.2014.05.042*

Razak, A. A., Hagishima, A., Ikegaya, N., \& Tanimoto, J. (2013). Analysis of airflow over building arrays for assessment of urban wind environment. Building and Environment, 59, 56-65. doi: 10.1016/j.buildenv.2012.08.007*

Santiago, J. L., \& Martin, F. (2005). Modelling the air flow in symmetric and asymmetric street canyons. International journal of environment and pollution, 25(1-4), 145-154. doi: 10.1504/IJEP.2005.007662*

Taleb, D., \& Abu-Hijleh, B. (2013). Urban heat islands: potential effect of organic and structured urban configurations on temperature variations in Dubai, UAE. Renewable energy, 50, 747-762. doi: 10.1016/j.renene.2012.07.030*

Xie, X., Huang, Z., \& Wang, J. S. (2005). Impact of building configuration on air quality in street canyon. Atmospheric Environment, 39(25), 4519-4530. doi: 10.1016/j.atmosenv.2005.03.043*

Yoshie, R., Mochida, A., Tominaga, Y., Kataoka, H., Harimoto, K., Nozu, T., \& Shirasawa, T. (2007). Cooperative project for CFD prediction of pedestrian wind environment in the Architectural Institute of Japan. Journal of wind engineering and industrial aerodynamics, 95(9-11), 1551-1578. doi: 10.1016/j.jweia.2007.02.023*

Yuan, C., Ng, E., \& Norford, L. K. (2014). Improving air quality in high-density cities by understanding the relationship between air pollutant dispersion and urban morphologies. Building and Environment, 71, 245-258. doi: 10.1016/j.buildenv.2013.10.008* 